\title{
Trustless libertarians? Attitudes about trust, politics, science and the environment in the blockchain community
}

\author{
Mélusine Boon-Falleur ${ }^{1}$ and Talia Laizeau ${ }^{2}$ \\ ${ }^{1}$ Institut Jean Nicod, Département d'études cognitives, ENS, PSL, EHESS, 75005 Paris, France \\ ${ }^{2}$ Université PSL, Paris, France
}

\begin{abstract}
:
Blockchain technology emerged in 2008 in the midst of the financial crisis to provide a decentralized alternative to financial institutions. Members of the blockchain community, including the pseudonymous inventor of the technology Satoshi Nokamoto, have often expressed low levels of trust toward traditional institutions such as central banks. In contrast, they argue that blockchain technology applications such as cryptocurrencies or decentralized autonomous organisations do not require the intervention of a third party and are therefore more trustworthy while also allowing for more freedom. In this context, members of the blockchain community are often described as trustless and libertarian. In this study, we tested whether members of the blockchain community indeed are different from the general population in terms of their attitudes toward trust, politics, science and the environment. We found that the blockchain community is less trusting of people and institutions, favors more private poverty, and is less pro-environmental than the general population. Given that trust in institutions has been decreasing in recent years, decentralized systems powered by blockchain technology may become appealing to a growing number of people around the world.
\end{abstract}

Keywords:

Blockchain, cryptocurrency, trust, environment, politics 


\section{Introduction}

In the middle of the 2008 financial crisis, the pseudonymous Satoshi Nokamoto wrote the Bitcoin White paper ${ }^{1}$, which would lead to the creation of blockchain technology. In his paper, he argued that the main issue with conventional currencies is that they require users to trust many different parties. For example, people must trust central banks not to debase the currency and trust commercial banks to hold enough reserves and make responsible investments. He argued that in contrast, blockchain technology allows the creation of a trustless system based on algorithmic reliability rather than human intervention. Since then, the popularity of blockchain technology has been increasing. In August 2021, there were a total of 75.6 million blockchain wallet users worldwide ${ }^{2}$, almost twice as many as there were in August 2019. Investments in blockchain technology have also soared in the past year. In the first quarter of 2021 alone, investors poured 2.6 billion dollars in blockchain startups around the world ${ }^{3}$, and the total market capitalization of cryptocurrencies passed the 2 trillion dollars bar in the summer ${ }^{4}$. Given the growing influence of blockchain technology in a large range of domains including finance, law, public services, supply chain, and space exploration, we are interested in understanding the attitudes and beliefs of the community building this technology ${ }^{5-7}$.

Blockchain technology emerged during a period of declining trust in many countries around the world ${ }^{8}$. It is often described as a "trustless system" which allows individuals to bypass issues associated with traditional institutions such as central banks and governments. It is therefore unsurprising that members of the blockchain community have often been described as anarcho-capitalists with low levels of trust ${ }^{9,10}$. The so-called "crypto bros" have also often been criticized for their individualistic and anti-social values as well as their ostensible display of wealth ${ }^{11}$. In addition, given the greenhouse gas emissions associated with mining blocks, the blockchain community is condemned for its lack of environmental concern ${ }^{12-14}$. Are such widely held clichés about the blockchain community justified? This question is important not 
only to understand who constitutes the blockchain community, but also to anticipate how it may grow and what sort of applications the community will seek to develop. In particular, we are interested in knowing whether members of the blockchain community differ significantly from the rest of the population in terms of their attitudes toward trust, politics, and science and the environment.

To date, very little data has been collected on the attitudes and beliefs of the blockchain community. Previous studies of members of the blockchain community have shown that they are predominantly male and dominated by libertarian/anarcho-capitalist political views ${ }^{15-18}$. Earlier surveys have shown that users are attracted to Bitcoin due to its anonymity, freedom and decentralization ${ }^{19}$. New users are generally motivated by curiosity, profit and politics, and report their experience as significantly more intellectually rewarding than socially rewarding. A study published by Hernandez and colleagues suggests the blockchain community is less socially inclined than the average person ${ }^{20}$. With previous studies pointing to a relatively asocial community, and blockchain's common description as a "trustless system", we are interested in determining if, in fact, the blockchain community is less trusting compared to the general population. Given that a low level of trust in institutions is often correlated with a low level of interpersonal trust, we are interested in measuring both types of trust within the blockchain community 21,22. Additionally, we attempt to sharpen the current understanding of the blockchain community's political beliefs to understand how present and future political trends might drive the technology's popularity and the use of cryptocurrencies. Lastly, we provide data on the attitudes toward science and the environment of the community. Given blockchain's heavy energy consumption, we are intrigued by the level of concern elicited by climate change and by the blockchain community's take on the future of this technology.

We collected data during the Ethereum Community Conference of 2021 ("EthCC"), the largest gathering of the Ethereum community taking place in person that year. Attendees of the conference were a mixture of developers, investors, entrepreneurs or simply blockchain enthusiasts, offering a diverse sample of the 
Ethereum community. Although some differences may exist between the EthCC attendees and the blockchain community at large, Ethereum is the largest blockchain network and supports many applications beyond cryptocurrencies. In order to identify differences in attitudes between the blockchain community and the general population, we compared answers from our EthCC sample to answers taken from the European Value Study (EVS), a large-scale, cross-national survey research programme providing insights into the ideas, beliefs, preferences, attitudes, values and opinions of citizens all over Europe ${ }^{23}$. To ensure the robustness of our results, we also compared answers from our EthCC sample to answers taken from the World Value Survey (WVS), a representative comparative social survey which is conducted globally every 5 years ${ }^{24}$. Our study provides the first analysis of the blockchain community's attitudes toward trust, politics, science and the environment. In addition, our study offers the first statistical comparison between the attitudes of the blockchain community and that of the general population.

\section{Methods}

Experimental design

We collected data during EthCC, which took place at the Maison de la Mutualité in Paris, from July 20th to July 22nd, 2021. 1,400 attendees from all over the world attended presentations from speakers on various issues, such as building decentralized autonomous organisations or solving legal issues surrounding the creation of new blockchain applications. During the conference, two researchers walked around the venue wearing a sign with a QR code, which conference attendees could scan to take a five minute survey (see Figure 1). Participation in the study was voluntary and participants had to give their informed consent before taking the survey. 


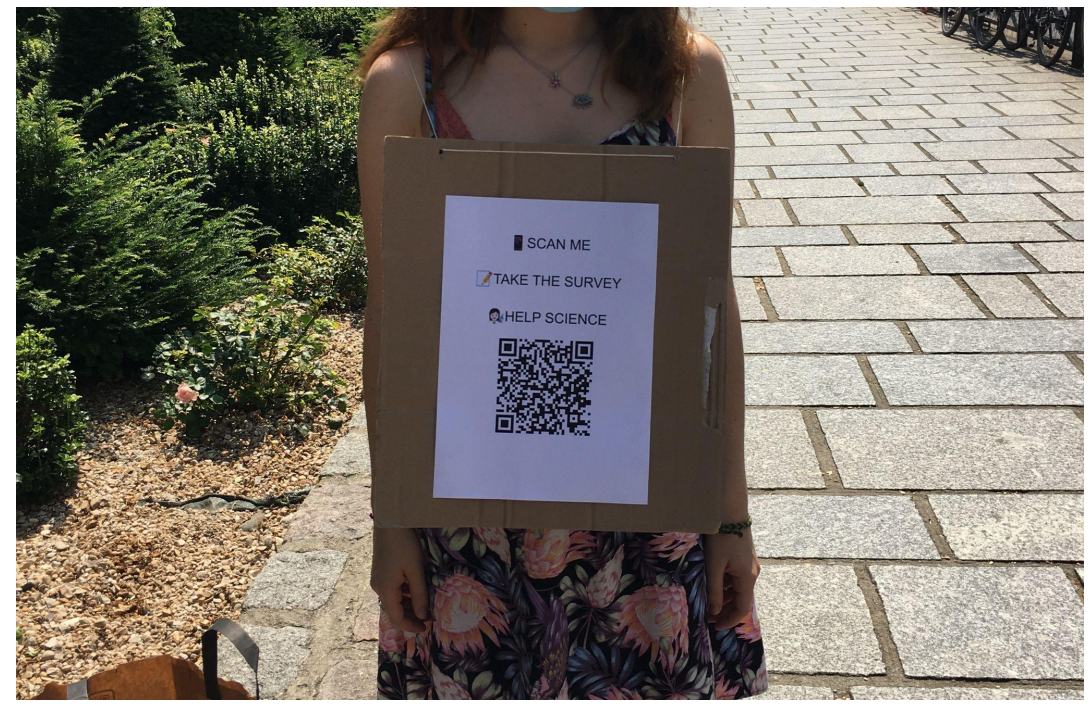

Figure 1: Researchers wearing a sign with the QR code for the online survey.

During the EthCC conference, two researchers walked around the venue wearing a sign with a QR code. Conference attendees were invited to scan the QR code and complete the online survey. Participation was voluntary and participants could decide to stop answering the survey at any point.

\section{Participants}

We collected data from a sample of 198 participants attending EthCC. Data is available on the OSF website at the following link https://osf.io/8h29k/. Participants in the study were approached during the conference and asked to take a survey on their attitudes regarding different topics. The research followed the guidelines of the declaration of Helsinki. The informed consent of participants' was obtained prior to the study. Participants could stop answering questions at any point. Out of the 198 participants taking the survey, 133 completed the optional demographics section, allowing us to gain a deeper understanding of the participants' profiles. The average age of participants was 31 years old $(\mathrm{SD}=7.87)$. The majority of respondents were from France (26\%) or the USA (18\%), although a total of 33 different nationalities were recorded in the survey. Many respondents had achieved a high level of education, with $45 \%$ completing 
postgraduate studies. Of the 132 respondents who provided demographic information, $11 \%$ were women. This is consistent with other studies of the blockchain community showing a low participation of women 19. We asked participants what their professions were and found that engineering and development were most often mentioned. When asked specifically about their role in the blockchain domain, most participants said they were developers ( $27 \%$ of participants). Participants were also asked when they had first started working in the blockchain domain, what their favorite aspect of blockchain is, and what sorts of problems blockchain technology can solve.

\section{Measures of trust}

In the first section of the survey, participants completed three different scales to measure trust. The first scale consisted of 5 questions adapted from the Rotter scale of interpersonal trust (see Appendix, Table A1). This scale measures whether people are suspicious of other people's intentions, whether they believe others are cynical and whether they believe other people are out to get as much as they can for themselves. For each question, respondents had to indicate how much they agreed with a statement using a 5 point Likert scale. The second scale measured interpersonal trust for five groups of people (e.g., family, people of a different nationality). The third scale measured trust in 11 different institutions such as trust in the justice system or trust in government. The second and third scales for trust were taken from the EVS, and had significant overlap with scales in the WVS. Participants answered using a 4 point likert scale. For each trust scale -- Rotter scale, interpersonal trust scale and trust in institutions scale -- a composite index was calculated as the mean of the answers to all questions, higher scores indicating more trust.

Measures of political attitudes 
The politics section of the survey consisted of 5 questions. The first question asked participants to rate their political orientation on a scale from 1 (the left) to 10 (the right). The next three questions related to attitudes on different topics, for example whether private ownership is better than public ownership (see Appendix Table A2 for a detail of the questions). The final question asked participants to rate their satisfaction with their country's political system on a scale from 1 (not satisfied at all) to 10 (completely satisfied). All measures were derived from questions present both in the EVS and WVS.

\section{Measures of science and environment attitudes}

For the first set of questions, participants were presented with five statements on environmental protection adapted from the EVS (e.g., "I would give part of my income if I were certain that the money would be used to prevent environmental pollution"). Participants had to rate how much they agreed with each statement using a five point Likert scale. A composite index was calculated as the mean of the answers to all questions, with higher scores indicating more pro-environmental attitudes. In the next section, participants had to choose amongst two statements the one that came closer to their point of view. The statements were the following (1) "Protecting the environment should be given priority, even if it causes slower economic growth and some loss of jobs" and (2) "Economic growth and creating jobs should be the top priority, even if the environment suffers to some extent". This question was adapted from both the EVS and WVS. The third set of questions asked participants about their attitude towards science and technology (see Appendix Table A3 for a detail of all questions). These questions were adapted from the WVS. Taken together, the answers to these questions give an idea of how important the environment and technological progress are to respondents.

\section{Comparison with the general population}


In order to compare the attitudes of the blockchain community to the general population, we used data from the fourth wave of the European Value Study, a longitudinal study taking place in different European countries measuring people's attitudes on a wide range of topics, including trust, politics and the environment ${ }^{23}$. We included in our study participants in the EVS that had answered all questions related to demographics, trust, politics and environmental attitudes, leading to a sample of 31,954 individuals. Given that attitudes toward trust, politics, science and the environment are highly correlated with the age, gender and educational attainment of individuals ${ }^{25-29}$, we created a subsample of respondents to the EVS that matched participants in our blockchain study on these variables. We made a 1:10 match, meaning that we matched each participant in the blockchain study with 10 participants in the EVS, leading to a total of 1320 individuals in our EVS sample. Although many of the EthCC attendees currently live in Europe, many of them came from countries all around the world. In order to account for the effect of country of origin, we replicated our analysis using answers from the World Value Survey, an extension of the EVS taking place around the globe. We included in our study WVS participants that had answered all questions related to demographics, trust, politics, science and environmental attitudes, leading to a sample of 41,419 individuals. We created a subsample of respondents to the EVS that matched participants in our blockchain study on age, gender, education and country of origin. Again, we made a 1:10 match, meaning that we matched each participant in the blockchain study with 10 participants in the EVS, leading to a total of 1210 individuals in our EVS sample (we dropped from the EthCC sample respondents who did not provide their country of origin).

\section{Results}

The blockchain community 
The majority of participants in our study started working in the blockchain community after 2017, meaning that they had only a few years of experience in this space (see Appendix Figure A1 for a complete distribution of the years participants joined the community). This is unsurprising given that blockchain is an emerging technology experiencing strong growth only recently. Among the participants' favorite aspects of blockchain, the following words were the most frequent: "freedom" (mentioned 25 times), "community" (mentioned 16 times) and "innovation" (mentioned 9 times, see Figure 2 for the full word cloud). Informal conversation with participants also revealed that their main reason for attending the conference was to meet new people and spend time with the community. The participants were mainly males $(89 \%)$, which echoes the differences in bitcoin literacy in the general population ${ }^{30}$.

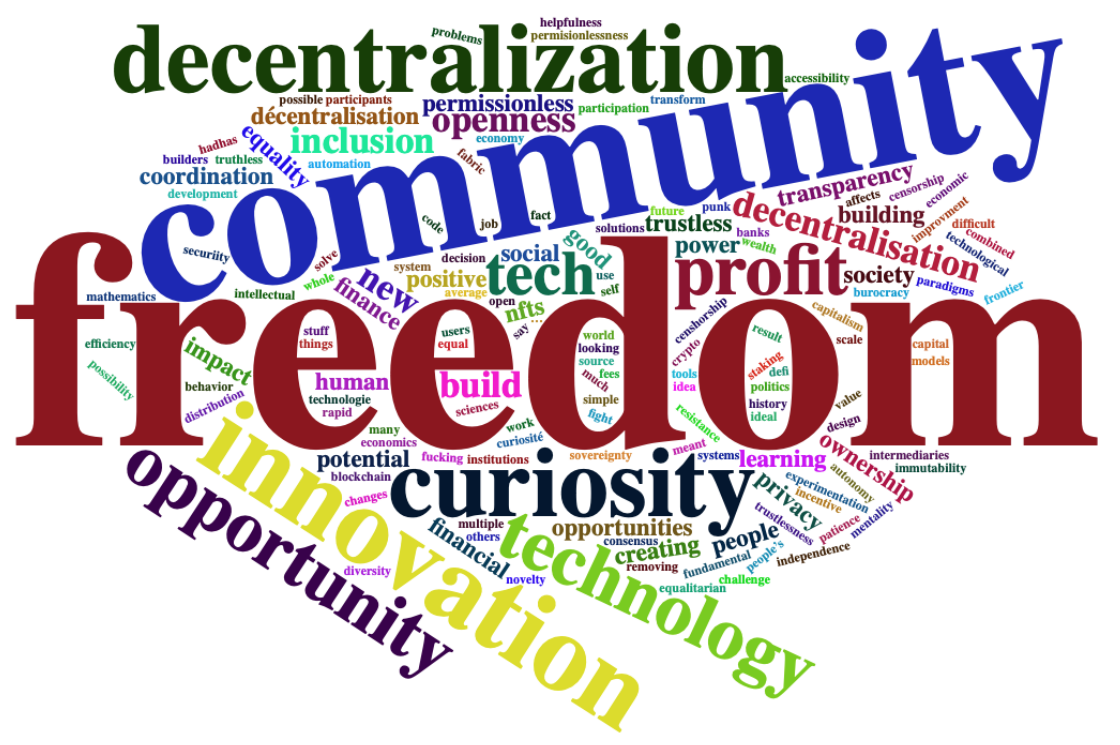

Figure 2: Respondent's favorite aspects of the blockchain community.

A word cloud was built based on respondents' answer to the question "What is your favorite aspect of the blockchain community". All answers were open ended. Larger words represent more occurences. $\mathrm{N}=128$. 


\section{Attitude toward trust}

The average score for the Rotter scale of interpersonal trust was $2.69(\mathrm{SD}=0.80, \mathrm{n}=191)$. This result points to a slight distrust of others, as a neutral response would be 3 . However, this result does not tell us whether the people in the blockchain community are less trusting than people in general. To find out, we compared the level of trust in the blockchain community to the level of trust in the general population. We first compared the average response of EthCC respondents and EVS respondents measures of interpersonal trust for different groups of people. Higher scores indicate lower trust towards any given group. Results show a difference in interpersonal trust between EthCC respondents and EVS respondents, with EthCC respondents being less trusting (difference $=0.25, \mathrm{p}=0.000$ ). For detailed comparison of results see Appendix Figure A2. We also asked EthCC respondents to rate how much they trust people in the blockchain community and people who use cryptocurrencies. We found that EthCC respondents trust people in the blockchain community and people who use cryptocurrencies more so than they trust people in their neighborhood or people they meet for the first time. We compared the average level of trust in institutions between EthCC respondents and EVS respondents. Again, we find that EthCC respondents are on average less trusting of institutions than EVS respondents (difference $=0.30, p=0.000$ ). Looking more closely at the responses, we find that no matter the institution, EthCC respondents trust that institution less than the average person does (see Appendix Figure A3 for detailed results). We performed the same analysis using the WVS matched sample and found similar results. Together, these results support the idea that people in the blockchain community are often anti-system and distrust powerful institutions. In addition to the institutions present in the EVS and WVS questionnaires, we also asked EthCC respondents whether they trusted the scientific community. We found that on average participants expressed quite a lot of confidence in the scientific community, suggesting that the level of trust depends on the type of institution (mean $=2.18, \mathrm{SD}=0.77, \mathrm{n}=168)$. 


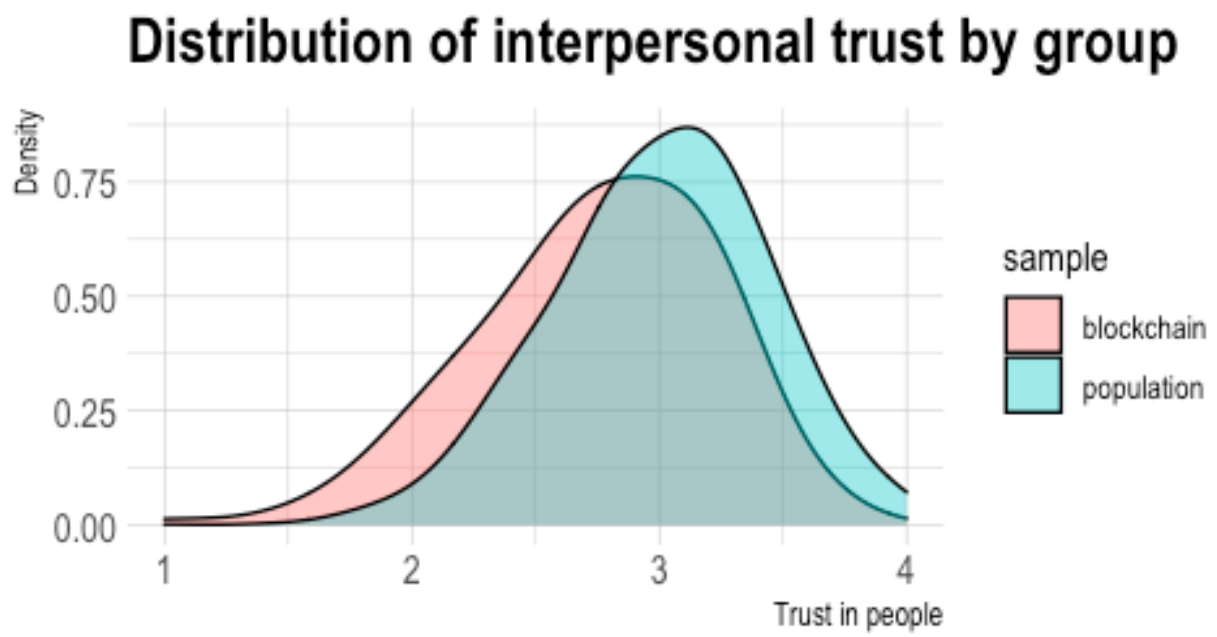

Figure 3a: Distribution of interpersonal trust by group (EVS).

Interpersonal trust was calculated as the mean of trust in five categories of individuals (your family, people in your neighborhood, people you know personally, people you meet for the first time and people of another nationality). Higher levels indicated more trust. The average interpersonal trust was 2.75 in the blockchain sample and 3.00 in the EVS sample (difference $=0.25, \mathrm{p}=0.000$ ). 


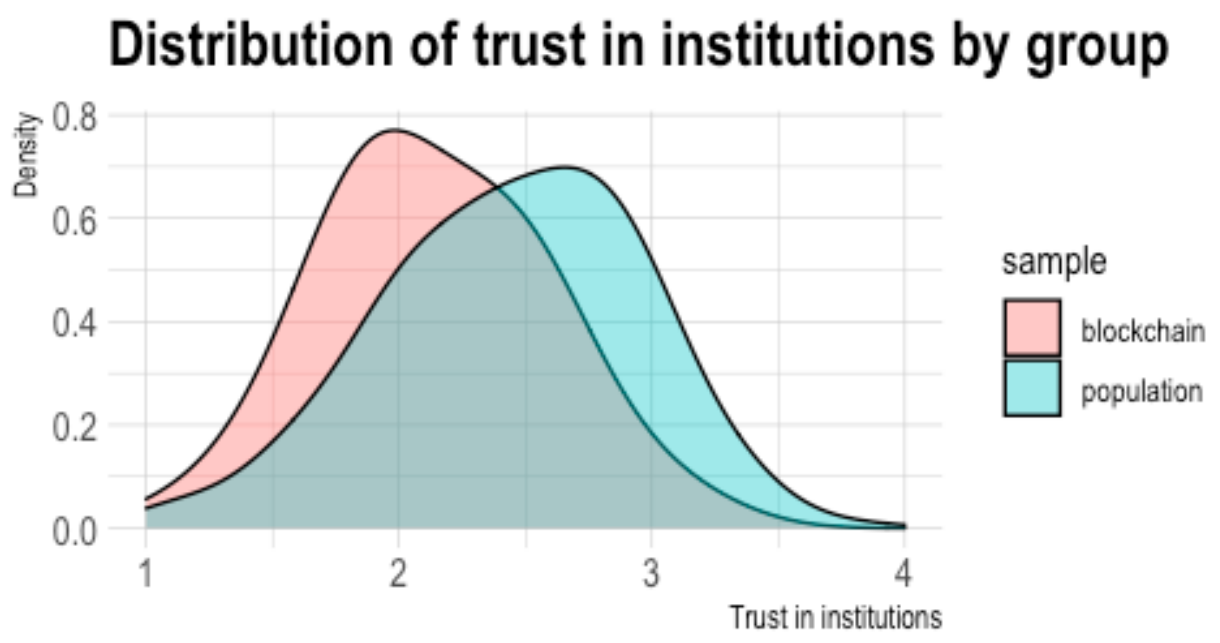

Figure 3b: Distribution of trust in institutions trust by group (EVS).

Trust in institutions was calculated as the mean of trust in ten institutions (the education system, the justice system, the healthcare system, the social security system, the police, government, major companies, environmental organisations, the press and social media). Higher levels indicated more trust. The average trust in institutions was 2.14 in the blockchain sample and 2.44 in the EVS sample (difference $=0.30, \mathrm{p}=0.000)$.

\section{Attitude toward politics}

We compared the political attitudes of EthCC respondents to those of EVS and WVS respondents. First, we found that on average, EthCC respondents are slightly more left-leaning than EVS respondents although the difference was not statistically significant (difference $=-0.34, p=0.076$ ). This goes against the view that members of the blockchain community are often right wing liberals. Looking more closely at respondents' political attitudes, we found no difference between EthCC respondents and EVS respondents on whether competition is good or harmful, and no difference on whether incomes should be made more equal. However, we did find that EthCC respondents believed that private ownership of 
business and industry should be increased more so than EVS respondents did (difference $=-0.45 \mathrm{p}=$ 0.026). Finally, looking at political satisfaction, we found that EthCC respondents are much less satisfied with how the political system is functioning in their country as compared to EVS respondents (difference $=-1.93, \mathrm{p}=0.000)$. Again, we found similar results when comparing the EthCC sample to the WVS sample, suggesting that even when we control for the country of origin, EthCC respondents are less satisfied with their government.

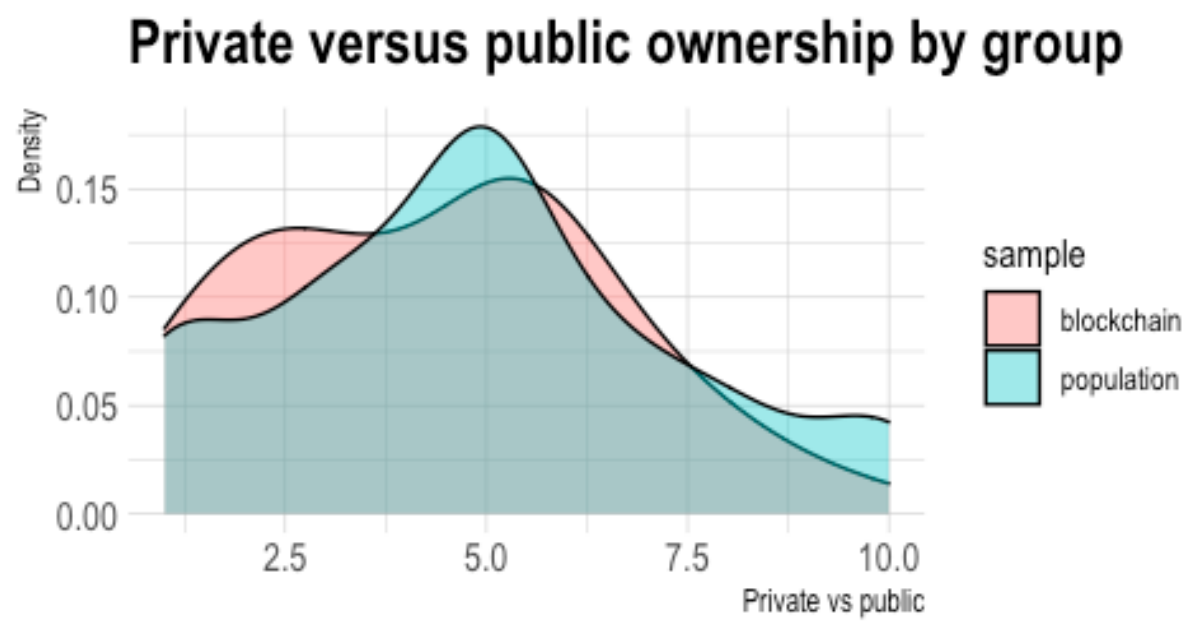

Figure 4a: Private versus public ownership by group (EVS).

Views on public versus private ownership were calculated on a scale from 1 (private ownership of business and industry should be increased) to 10 (government ownership of business and industry should be increased). Higher scores thus indicate more favorable views towards public ownership. The average attitude towards ownership was 4.38 in the blockchain sample and 4.83 in the EVS sample (difference= $0.45, \mathrm{p}=0.026)$ 


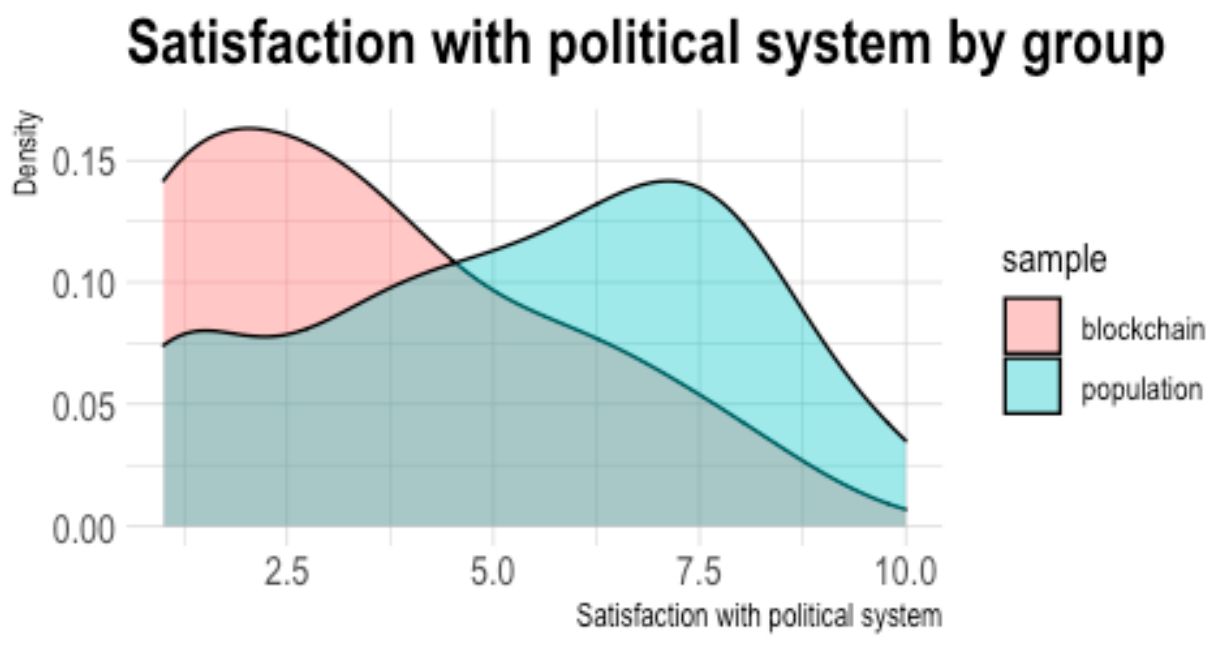

Figure 4b: Satisfaction with the political system by group (EVS).

Satisfaction with the political system in the country of the respondent was calculated on a scale from 1 (not satisfied at all) to 10 (completely satisfied). Higher scores thus indicate more satisfaction towards the political system. The average attitude towards ownership was 3.43 in the blockchain sample and 5.36 in the EVS sample (difference $=1.96, \mathrm{p}=0.000)$.

Attitude toward science and the environment

We compared the attitudes toward science and the environment of EthCC respondents to those of EVS and WVS respondents. We found that EthCC respondents care less about the environment than EVS respondents do $($ difference $=0.37, p=0.000)$. We also found that a higher portion of EthCC respondents believe that economic growth and creating jobs should be the top priority, even if the environment suffers to some extent (difference $=17 \%, \mathrm{p}=0.000)$. However, when comparing the EthCC sample to the WVS sample, we found that on the contrary, a larger portion of the EthCC sample believe that protecting the 
environment should be given priority (difference $=26 \%, \mathrm{p}=0.000$ ). From these results, it appears that on one hand people in the blockchain community are not as pro-environmental as their general population counterparts, yet they may still prioritize the environment over economic growth and creating jobs. We also looked at attitudes concerning science and technology and found that EthCC respondents believe that science and technology are making our lives healthier, easier, and more comfortable, more so than their WVS counterparts (difference $=0.60, \mathrm{p}=0.003$ ). EthCC respondents also agree that because of science and technology, there will be more opportunities for the next generation (mean $=8.00, \mathrm{SD}=2.27, \mathrm{n}=$ 141), but they did not differ from WVS respondents in that respect. Finally, we asked respondents whether all things considered, they would say that the world is better off, or worse off, because of science and technology. Again, EthCC respondents agreed more that the world is better off because of science and technology than their WVS counterparts (difference $=0.88, \mathrm{p}=0.000$ ). We also directly asked participants what they believed blockchain technology can do. Respondents could select one or more answers among four existing options, or enter their own response. Among the existing responses, $70 \%$ of participants chose "propel economic growth", $60 \%$ chose "quench inequalities between richer and poorer countries", $35 \%$ chose "improve healthcare" and 23\% chose "mitigate climate change". Together, these results show that the blockchain community places a high level of confidence on technology to solve some of the world's most pressing problems. 


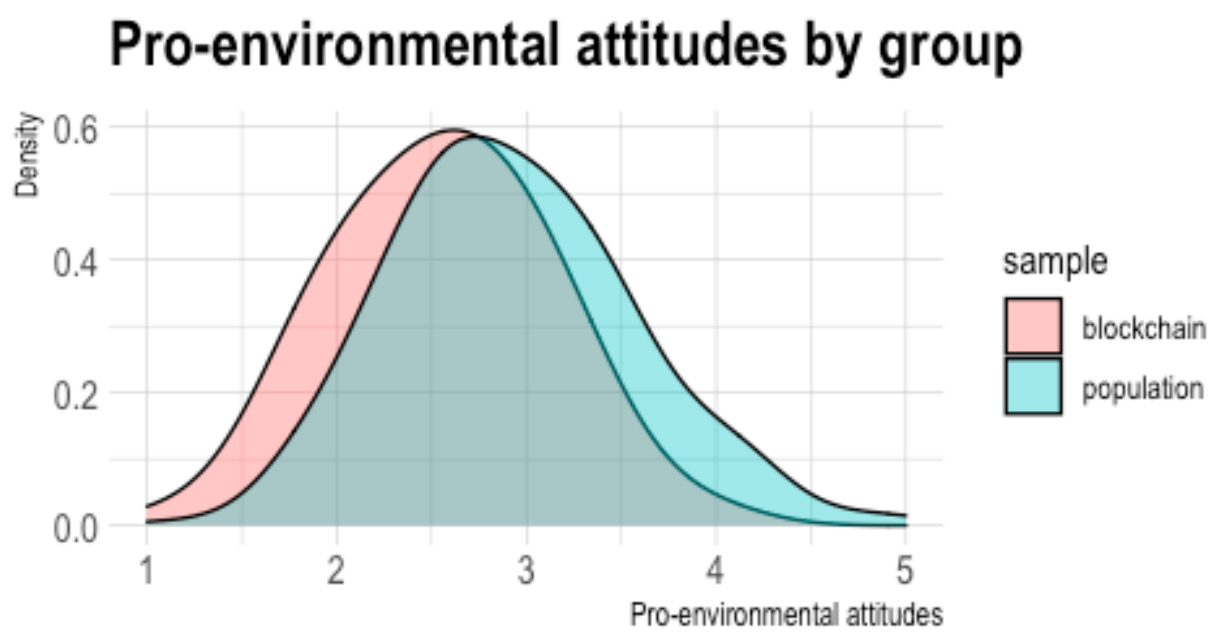

\section{Figure 5: Pro-environmental attitudes by group (EVS).}

Pro-environmental attitudes were calculated using five statements on environmental protection adapted from the EVS (e.g., "I would give part of my income if I were certain that the money would be used to prevent environmental pollution"). Participants had to rate how much they agreed with each statement using a five point Likert scale. A composite index was calculated as the mean of the answers to all questions, with higher scores indicating more pro-environmental attitudes. The average attitude towards the environment was 2.55 in the blockchain sample and 2.92 in the EVS sample (difference $=0.37, \mathrm{p}=$ $0.000)$.

\section{Discussion}

The aim of our study was to identify any differences in the attitude toward trust, politics, science and the environment between the blockchain community and the general population. To do so, we compared members of the blockchain community attending an Ethereum conference to a subsample of respondents 
to the EVS and the WVS, which were matched on gender, age, educational attainment and nationality. Our results support the idea that members of the blockchain community are less trusting of both people and institutions. Regarding political attitudes, members of the blockchain community are slightly more left-wing than the general population, a finding that questions the right-wing liberal stereotype. However, they also support more private ownership, which is consistent with a liberal ideology. Turning to attitudes toward science and the environment, people in the blockchain community care less about the environment and believe that economic growth is more important than people in the general population do, which echoes some criticisms made about the environmental footprint of blockchain technology. Finally, from our survey, it seems that people in the blockchain community place a lot of confidence in science and technology, and believe that blockchain can be a solution to a wide range of issues.

There are however a few limitations to our study. First, given the voluntary nature of this study, it is possible that respondents to our survey were more prosocial than the average attendees of EthCC. Given that prosociality is correlated to trust, our biased sample could lead to an underestimation of the difference in trust between the blockchain community and the general population. In other words, the blockchain community could be even less trusting compared to the average person than our results have shown. Second, EthCC attendees may not be representative of the blockchain community at large. A number of articles have pointed to the differences between different communities within the blockchain space ${ }^{31}$. Members of the Ethereum community are usually perceived as being less anti-system than, for example, people who only use bitcoins. As a result, our sample may be more trusting and more left-wing than the blockchain community at large. Finally, answers in the EVS and WVS samples were collected in 2017, so that there is a 4 year temporal difference between the data collected at the EthCC conference and the data collected in the EVS or WVS. Such temporal differences could affect for example pro-environmental attitudes, which may have increased in the general population since 2017. 
There are a number of important avenues for future research. First, further studies should be conducted on different sub groups of the blockchain community, in order to be representative of the whole ecosystem. For this study, only self-reported data was collected. Further studies should measure people's attitudes and preferences through behavioral data, such as trust games. In addition, more work should be done to understand the environmental attitudes of members of the blockchain community. Indeed, one reason members of the blockchain community appear to care less about the environment may be that they do not trust the current system to solve environmental issues. This could lead people in the blockchain community to have no motivation for climate change mitigation. Given the high trust in the scientific community, it would be interesting to test whether people in blockchain agree with climate scientists and support solutions proposed by the scientific community.

\section{Conclusion}

Our study demonstrated that some of the clichés about the blockchain community are true: people are less trusting, they support private property, care less about the environment and believe that technological progress can solve many problems. Given the decline in trust in institutions in recent years in many countries around the world, it is likely that more and more individuals will be attracted to blockchain technology to limit the power of certain institutions such as central banks. This trend could push institutions to change the way they operate and adopt more decentralized modes of governance, or even lead to the creation of blockchain-based virtual nations ${ }^{32}$. In addition, although the blockchain community is characterized by low trust, it appears to be less biased against foreigners than the average person. This could lead to more cooperation across national boundaries, supported by new institutions such as Decentralized Autonomous Organisations. Finally, the attitudes of the blockchain community also matter for the future of the technology. We could expect that many blockchain applications will be developed to replace traditional institutions and that efforts to reduce the environmental impact of blockchain technology might be scarce in the absence of incentives. 


\section{References}

1. Nakamoto, S. Bitcoin: A Peer-to-Peer Electronic Cash System. Decentralized Bus. Rev. 21260, 9 (2008).

2. de Best, R. Blockchain wallets 2011-2021. Statista https://www.statista.com/statistics/647374/worldwide-blockchain-wallet-users/ (2021).

3. Liu, S. Global blockchain startup financing history 2021. Statista https://www.statista.com/statistics/621207/worldwide-blockchain-startup-financing-history/ (2021).

4. Total Cryptocurrency Market Cap Stays Above \$2 Trillion Despite Recent Losses. https://finance.yahoo.com/news/total-cryptocurrency-market-cap-stays-091218829.html?guccounter= 1\&guce_referrer=aHR0cHM6Ly93d3cuZ29vZ2x1LmNvbS8\&guce_referrer_sig=AQAAABZWBAJk 3fWFsErI3rAh15M405gP4M7qvvzuMz_BDF4_2B5T9ki5mZ7B5SKD30pqQjF2ANVdO96G8QE6 HpoioKIVgWJ5rbuCtxr7HclLyKghAZF4nPCJRGhJTcJwm9fVj1xK8L42FO-SLjtvxwAh1GkECEb0 tAGKaNcNeW_aZqPq (2021).

5. Atzori, M. Blockchain Technology and Decentralized Governance: Is the State Still Necessary? https://papers.ssrn.com/abstract=2709713 (2015) doi:10.2139/ssrn.2709713.

6. Ferreira, J. P. M., Gonçalves, M. J. A. \& da Silva, A. F. A Systematic Literature Review in Blockchain: Benefits and Implications of the Technology for Business. in New Knowledge in Information Systems and Technologies (eds. Rocha, Á., Adeli, H., Reis, L. P. \& Costanzo, S.) 405-414 (Springer International Publishing, 2019). doi:10.1007/978-3-030-16181-1_38.

7. Tredinnick, L. Cryptocurrencies and the blockchain. Bus. Inf. Rev. 36, 39-44 (2019).

8. Hosking, G. The decline of trust in government. in Trust in Contemporary Society 77-103 (Brill, 2019).

9. Forget far-right populism - crypto-anarchists are the new masters. the Guardian http://www.theguardian.com/technology/2017/jun/04/forget-far-right-populism-crypto-anarchists-arethe-new-masters-internet-politics (2017). 
10. Husain, S. O., Franklin, A. \& Roep, D. The political imaginaries of blockchain projects: discerning the expressions of an emerging ecosystem. Sustain. Sci. 15, 379-394 (2020).

11. Bloomberg. As Bitcoin Sinks, Crypto Bros Party Hard on a Blockchain Cruise. Bloomberg.com https://www.bloomberg.com/news/articles/2018-01-19/as-bitcoin-sinks-crypto-bros-party-hard-on-ablockchain-cruise (2018).

12. Gallersdörfer, U., Klaaßen, L. \& Stoll, C. Energy Consumption of Cryptocurrencies Beyond Bitcoin. Joule 4, 1843-1846 (2020).

13. Mohsin, M., Naseem, S., Zia-ur-Rehman, M., Baig, S. A. \& Salamat, S. The crypto-trade volume, GDP, energy use, and environmental degradation sustainability: An analysis of the top 20 crypto-trader countries. Int. J. Finance Econ. n/a, 1-17 (2020).

14. Stoll, C., Klaaßen, L. \& Gallersdörfer, U. The Carbon Footprint of Bitcoin. Joule 3, 1647-1661 (2019).

15. Bashir, M., Strickland, B. \& Bohr, J. What Motivates People to Use Bitcoin? in Social Informatics (eds. Spiro, E. \& Ahn, Y.-Y.) 347-367 (Springer International Publishing, 2016). doi:10.1007/978-3-319-47874-6_25.

16. Google Analytics Reveal Surprising Bitcoin Demographics. Bitcoinist.com https://bitcoinist.com/google-analytics-bitcoin-demographics/ (2019).

17. Live Free or Mine: How Libertarians Fell in Love With Bitcoin - CoinDesk. https://www.coindesk.com (2016).

18. Yelowitz, A. \& Wilson, M. Characteristics of Bitcoin users: an analysis of Google search data. Appl. Econ. Lett. 22, 1030-1036 (2015).

19. Overview of Bitcoin Community Survey Feb-Mar 2013. Simulacrum https://simulacrum.cc/en/overview-of-bitcoin-community-survey-feb-mar-2013/ (2013).

20. Hernandez, I., Bashir, M., Jeon, G. \& Bohr, J. Are Bitcoin Users Less Sociable? An Analysis of Users' Language and Social Connections on Twitter. in HCI International 2014 - Posters'Extended Abstracts (ed. Stephanidis, C.) 26-31 (Springer International Publishing, 2014). 
doi:10.1007/978-3-319-07854-0_5.

21. Domański, H. \& Pokropek, A. The Relation between Interpersonal and Institutional Trust in European Countries: Which Came First? Pol. Sociol. Rev. 213, 87-102 (2021).

22. Ortiz-Ospina, E. \& Roser, M. Trust. Our World Data (2016).

23. Gedeshi, I. et al. European Values Study 2017: Integrated Dataset (EVS 2017). '. (2020).

24. Haerpfer, C. et al. World Values Survey: Round Seven - Country- Pooled Datafile. JD Syst. Inst. WVSA Secr. (2020) doi:doi.org/10.14281/18241.1.

25. Brandt, M. J., Wetherell, G. \& Henry, P. J. Changes in Income Predict Change in Social Trust: A Longitudinal Analysis. Polit. Psychol. 36, 761-768 (2015).

26. Drummond, C. \& Fischhoff, B. Individuals with greater science literacy and education have more polarized beliefs on controversial science topics. Proc. Natl. Acad. Sci. 114, 9587-9592 (2017).

27. Emler, N. \& Frazer, E. Politics: The education effect. Oxf. Rev. Educ. 25, 251-273 (1999).

28. Gifford, R. The dragons of inaction: Psychological barriers that limit climate change mitigation and adaptation. Am. Psychol. 66, 290-302 (2011).

29. Schoon, I., Cheng, H., Gale, C. R., Batty, G. D. \& Deary, I. J. Social status, cognitive ability, and educational attainment as predictors of liberal social attitudes and political trust. Intelligence $\mathbf{3 8}$, $144-150$ (2010).

30. Bannier, C., Meyll, T., Röder, F. \& Walter, A. The gender gap in 'Bitcoin literacy'. J. Behav. Exp. Finance 22, 129-134 (2019).

31. From Doge Soldiers to Bitcoinists: A Field Guide to the Crypto Faithful. Bloomberg.com (2021).

32. De Filippi, P. Citizenship in the Era of Blockchain-Based Virtual Nations. in Debating Transformations of National Citizenship (ed. Bauböck, R.) 267-277 (Springer International Publishing, 2018). doi:10.1007/978-3-319-92719-0_48. 


\section{Appendix}

Table A1: Interpersonal Trust Scale.

The items in the scale have been adapted from J. Rotter, "A New Scale for the Measurement of Interpersonal Trust," Journal of Personality (1967).

Questions

In dealing with strangers, one is better off to be cautious until they have provided evidence that they are trustworthy.

It is safe to believe that in spite of what people say, most people are primarily interested in their own welfare.

In these competitive times one has to be alert or someone is likely to take advantage of you.

Most people can't be counted on to do what they say they will do.

Most idealists are not sincere and usually do not practice what they preach.

\section{Table A2: Political Attitude Questions}

The political attitude section of the survey consisted of the following questions. For each question, participants had to select an answer on a scale from 1 to 10 .

\section{Political attitude questions}

In political matters, people talk of 'the left' and 'the right'. How would you place your views on this 
scale, generally speaking? ( 1 is left, 10 is right)

Please read the following statements and indicate where you would place your views on this scale:

(1) Competition is good

(10) Competition is harmful

(1) Incomes should be made more equal

(10) There should be greater incentives for individual effort

(1) Private ownership of business and industry

(10) Government ownership of business and should be increased industry should be increased

On a scale from 1 to 10 where " 1 " is "not satisfied at all" and " 10 " is "completely satisfied", how satisfied are you with how the political system is functioning in your country these days?

\section{Table A3: Attitudes Toward Science and the Environment Questions}

The first set consisted of five statements regarding people's attitude toward environmental protection. Participants answered using a five point Likert scale. A composite index was calculated as the mean of the answers to all questions, with higher scores indicating more pro-environmental attitudes. In the next set of questions, participants had to choose amongst two statements the one that came closer to their point of view. The third set of questions asked participants about their attitude on science and technology.

Attitudes Toward Science and the Environment Questions

How much do you agree or disagree with each of these statements?

- I would give part of my income if I were certain that the money would be used to prevent environmental pollution. 
- It is just too difficult for someone like me to do much about the environment.

- It is just too difficult for someone like me to do much about the environment.

- There is no point in doing what I can for the environment unless others do the same.

- Many of the claims about environmental threats are exaggerated.

( 1 is strongly disagree, 5 is strongly agree)

Here are two statements people sometimes make when discussing the environment and economic growth. Which of them comes closer to your own point of view?

(1) Protecting the environment should be given priority, even if it causes slower economic growth and some loss of jobs

(2) Economic growth and creating jobs should be the top priority, even if the environment suffers to some extent

Please indicate how much you agree or disagree with each of the following statements:

- Science and technology are making our lives healthier, easier, and more comfortable.

- Because of science and technology, there will be more opportunities for the next generation.

( 1 is completely disagree, 10 is completely agree)

All things considered, would you say that the world is better off, or worse off, because of science and technology? Please indicate which come closest to your view on this scale:

( 1 is A lot worse off, 10 is A lot better off)

\section{Figure A1: Distribution of date of entry in the blockchain community}

We asked participants when they first started working in the Blockchain domain. We find that most participants started after 2017, which is normal given the recency of the technology. 


\section{Distribution of year of entry in blockchain community}

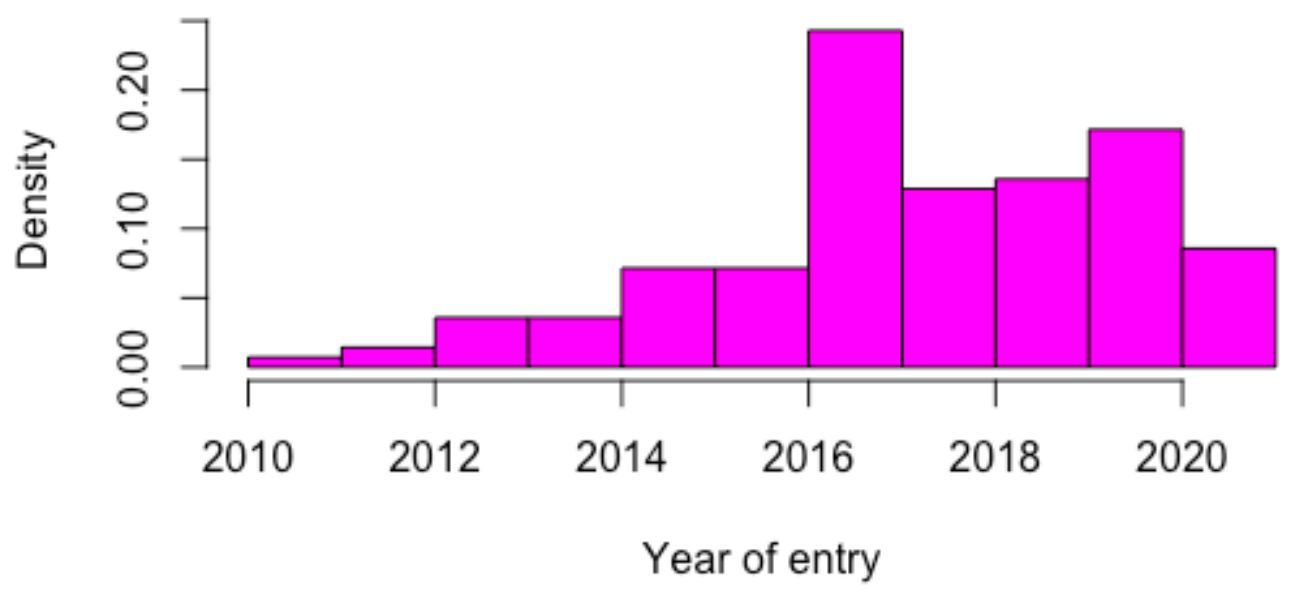

Figure A2.a: Trust in people in the blockchain community and in the general population (EVS)

This figure displays the average level of trust for five categories of individuals (your family, people in your neighborhood, people you know personally, people you meet for the first time and people of another nationality) for the blockchain community and the general population. T-test comparisons of the mean were performed for each category of individuals. Significance level are represented with stars on the chart $(* \mathrm{p}=0.05, * * \mathrm{p}=0.01, * * * \mathrm{p}=0.001, * * * * \mathrm{p}=0.0001)$. 


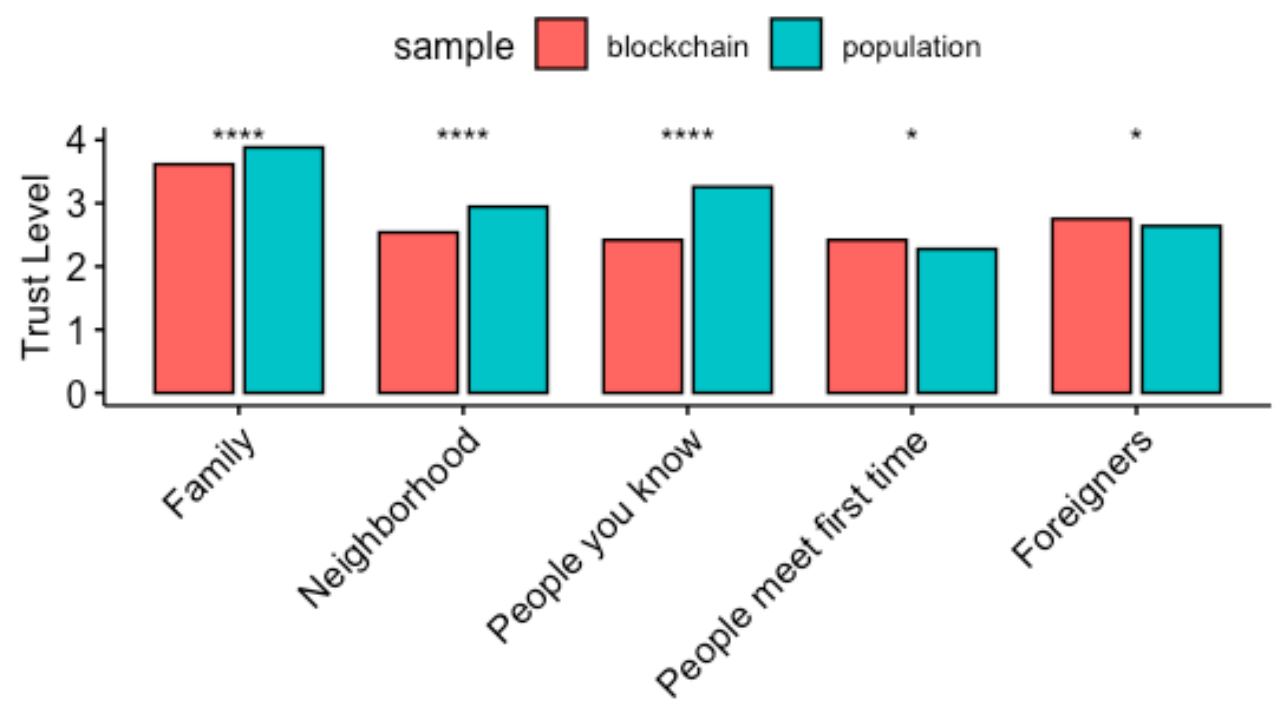

Figure A2.b: Trust in people in the blockchain community and in the general population (WVS)

This figure displays the average level of trust for five categories of individuals (your family, people in your neighborhood, people you know personally, people you meet for the first time and people of another nationality) for the blockchain community and the general population. T-test comparisons of the mean were performed for each category of individuals. Significance level are represented with stars on the chart $(* \mathrm{p}=0.05, * * \mathrm{p}=0.01, * * * \mathrm{p}=0.001, * * * * \mathrm{p}=0.0001)$. 


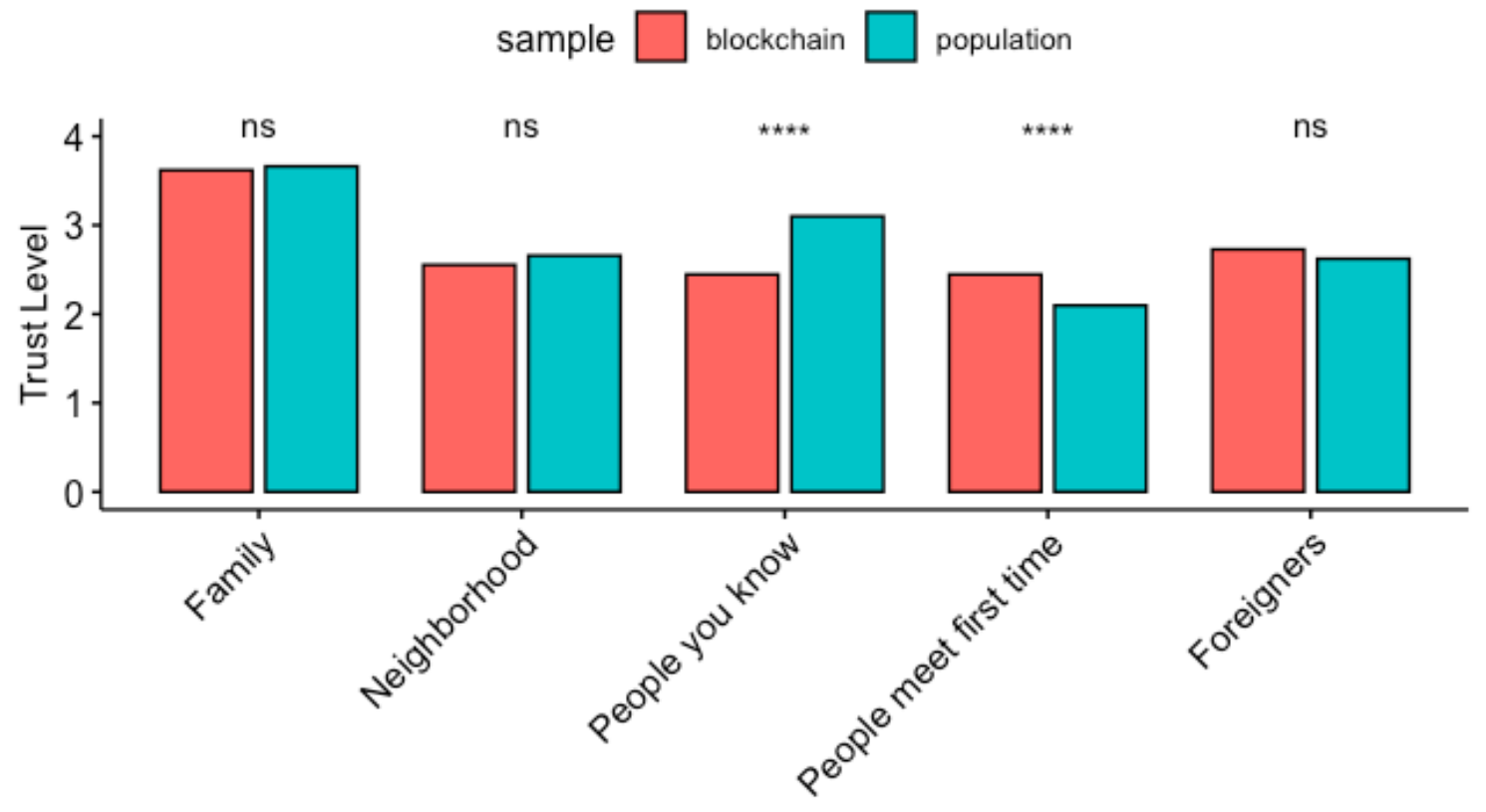

Figure A3.a: Trust in institutions in the blockchain community and in the general population (EVS) 
This figure displays the average level of trust for ten categories of institutions (the education system, the justice system, the healthcare system, the social security system, the police, government, major companies, environmental organisations, the press and social media) for the blockchain community and the general population. T-test comparisons of the mean were performed for each category of individuals. Significance level are represented with stars on the chart $(* \mathrm{p}=0.05, * * \mathrm{p}=0.01, * * * \mathrm{p}=0.001, * * * *$ $\mathrm{p}=0.0001)$.

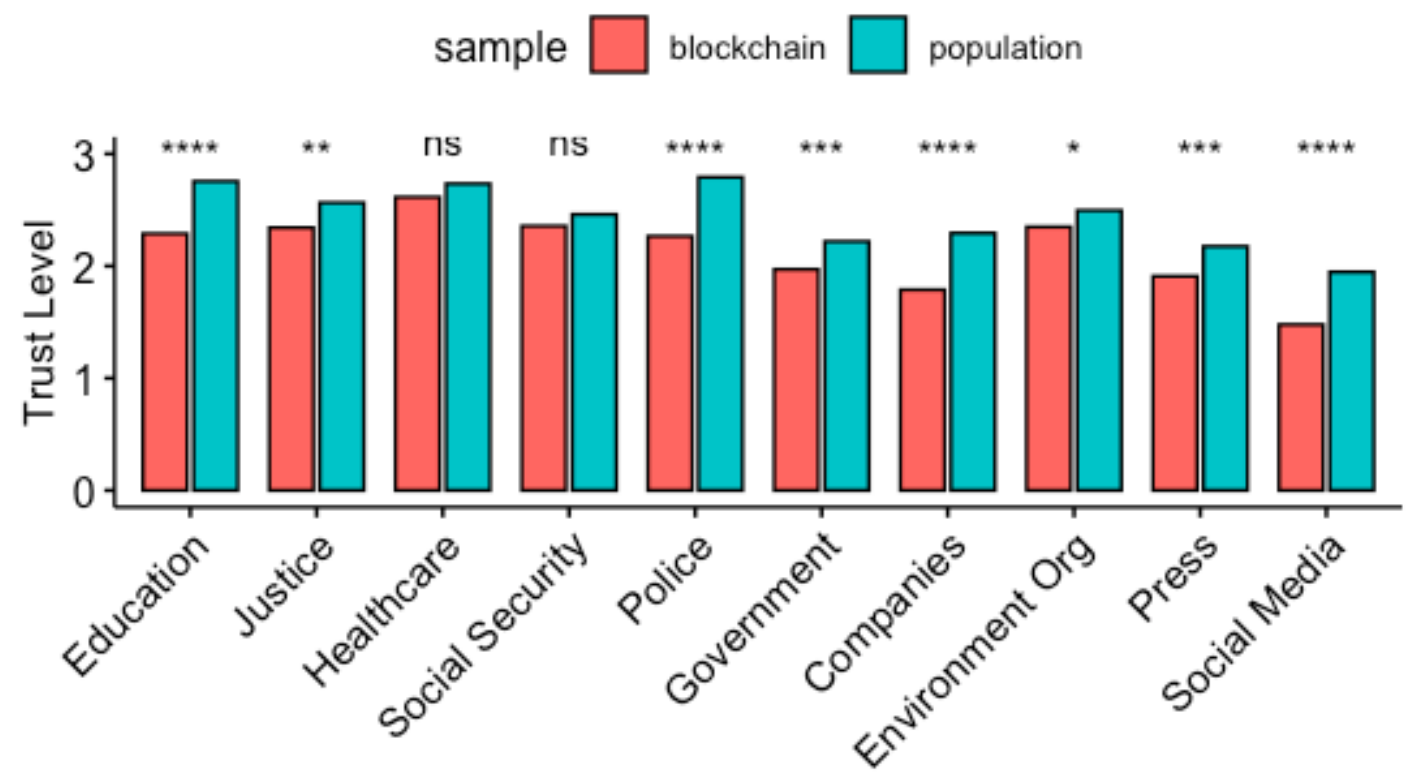

Figure A3.a: Trust in institutions in the blockchain community and in the general population (WVS)

This figure displays the average level of trust for ten categories of institutions for the EthCC sample and the WVS sample. In some cases, there wasn't an exact match for the institution, so that pairs of institutions were formed as following: the education system/universities, the justice system/courts, the healthcare system/ the WHO, the social security system/civil servants, the police, government, major companies, environmental organisations, and the press) for the blockchain community and the general 
population. T-test comparisons of the mean were performed for each category of individuals. Significance level are represented with stars on the chart $(* \mathrm{p}=0.05, * * \mathrm{p}=0.01, * * * \mathrm{p}=0.001, * * * * \mathrm{p}=0.0001)$.

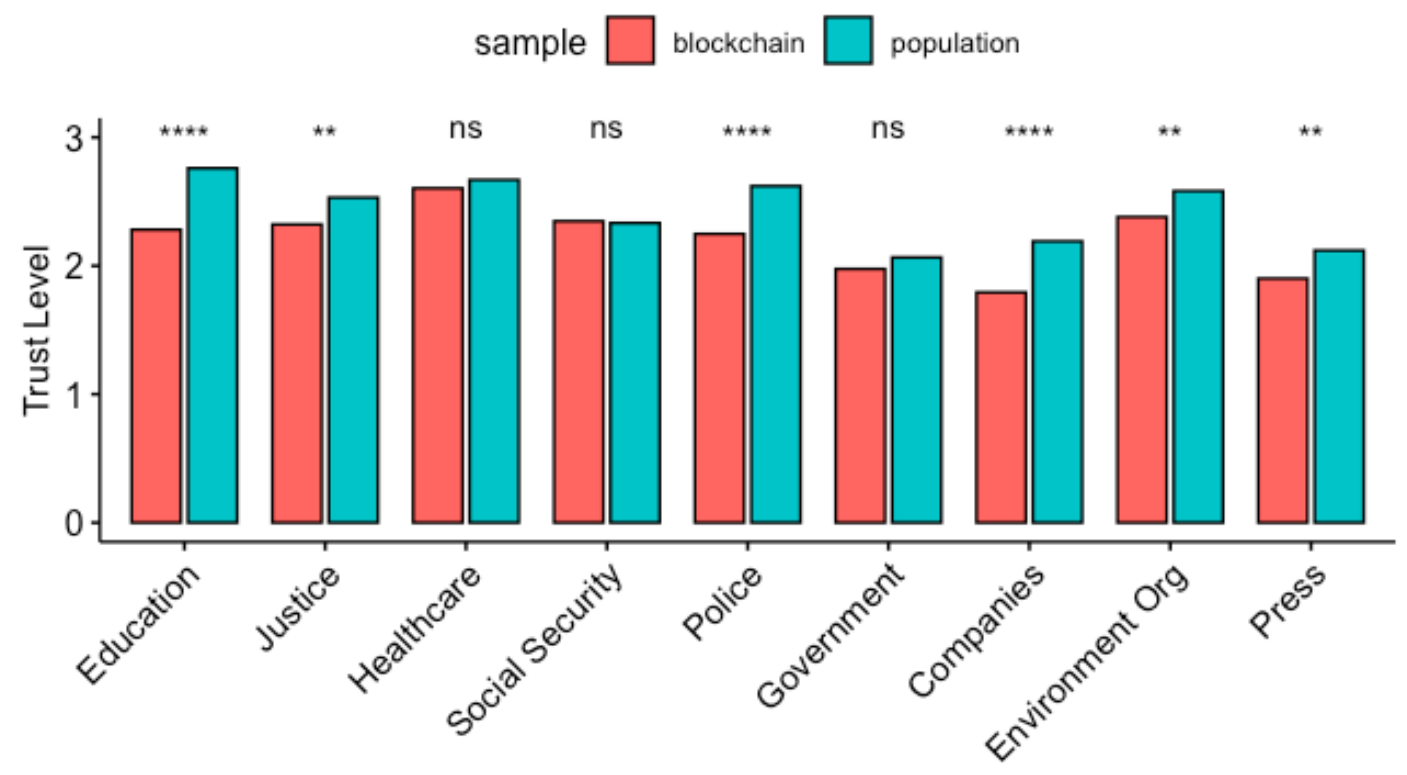

Figure A4.a: Left-right political orientation by group (EVS)

Political orientation was calculated on a scale from 1 (left) to 10 (right). Higher scores thus indicate more right-leaning political orientation. The average political orientation was 5.10 in the blockchain sample and 5.44 in the EVS sample (difference $=0.34, \mathrm{p}=0.076$ ). 


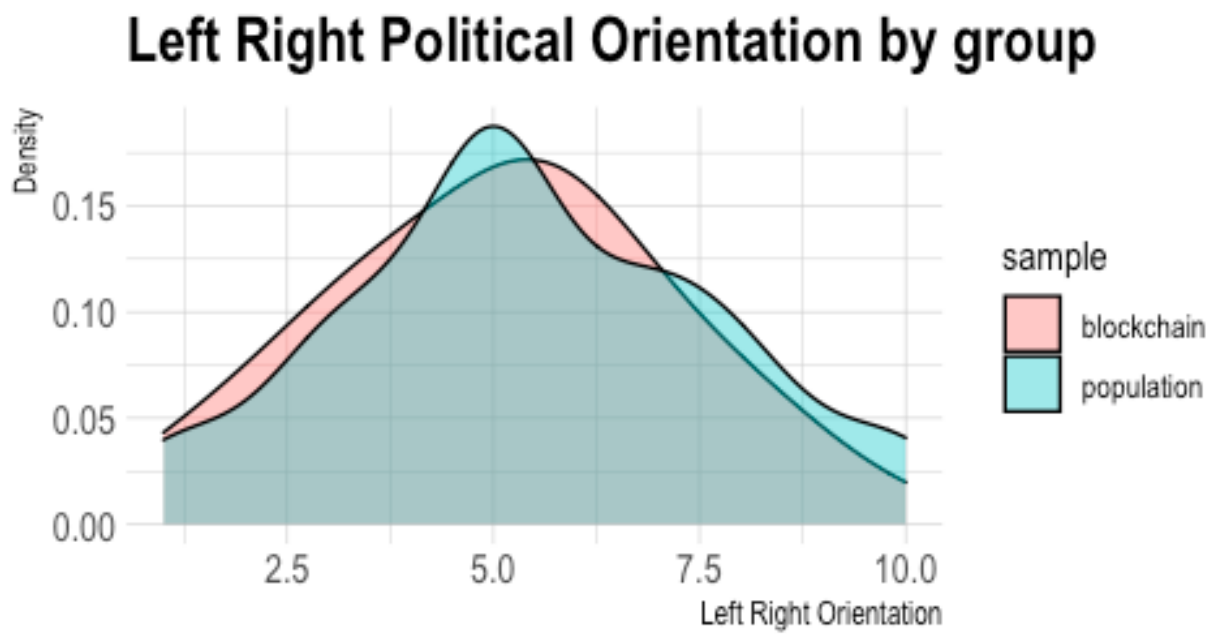

Figure A4.b: Left-right political orientation by group (WVS)

Political orientation was calculated on a scale from 1 (left) to 10 (right). Higher scores thus indicate more right-leaning political orientation. The average political orientation was 5.04 in the blockchain sample and 5.11 in the WVS sample (difference $=0.07, \mathrm{p}=0.723$ ).

Left Right Political Orientation by group

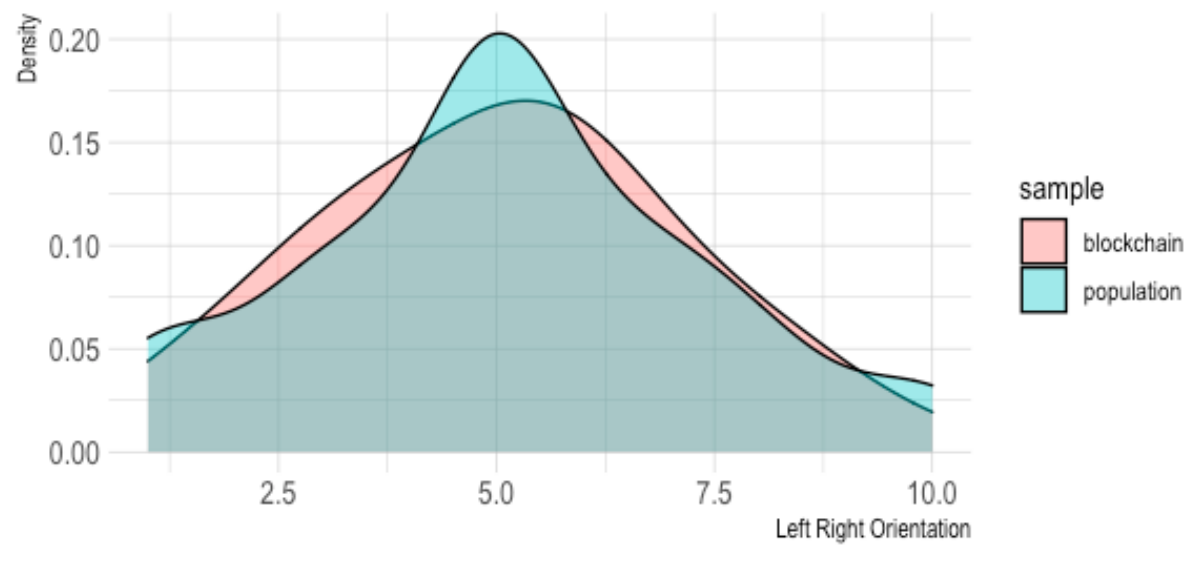


Figure A5.a: Views on competition by group (EVS).

Views on competition were calculated on scale from 1 (competition is good) to 10 (competition is harmful). Higher scores thus indicate worse views on competition. The average view on competition was 3.08 in the blockchain sample and 3.29 in the EVS sample (difference $=0.11, \mathrm{p}=0.238)$.

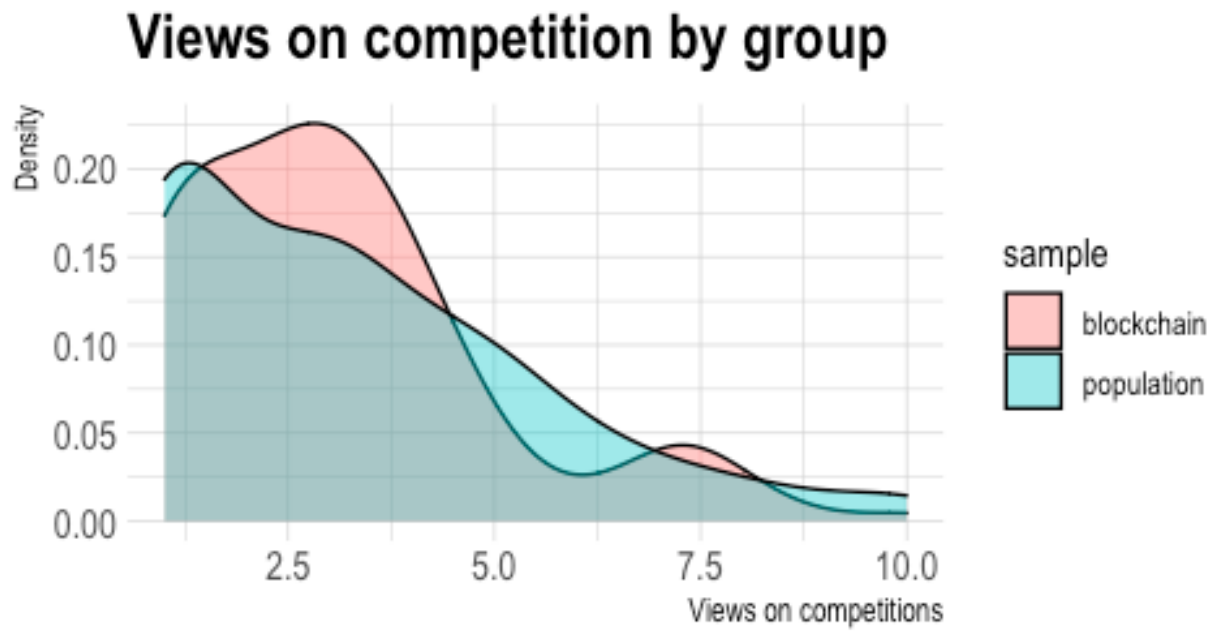

Figure A5.b: Views on competition by group (WVS).

Views on competition were calculated on scale from 1 (competition is good) to 10 (competition is harmful). Higher scores thus indicate worse views on competition. The average view on competition was 3.08 in the blockchain sample and 3.45 in the WVS sample (difference $=0.37, \mathrm{p}=0.054$ ). 


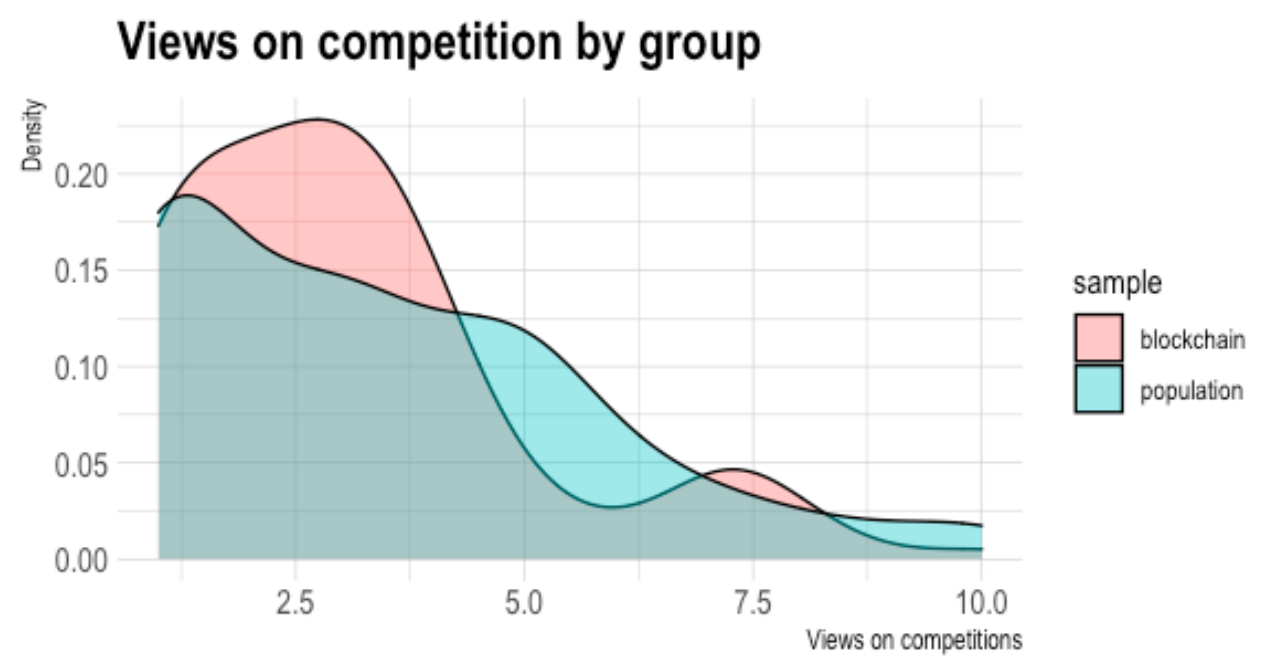

Figure A6.a: Views on income redistribution by group (EVS).

Views on income redistribution were calculated on scale from 1 (incomes should be made more equal) to 10 (there should be greater incentives for individual effort). Higher scores thus indicate less support for redistribution. The average view on income redistribution was 5.77 in the blockchain sample and 6.03 in the EVS sample (difference $=0.26, \mathrm{p}=0.285)$. 


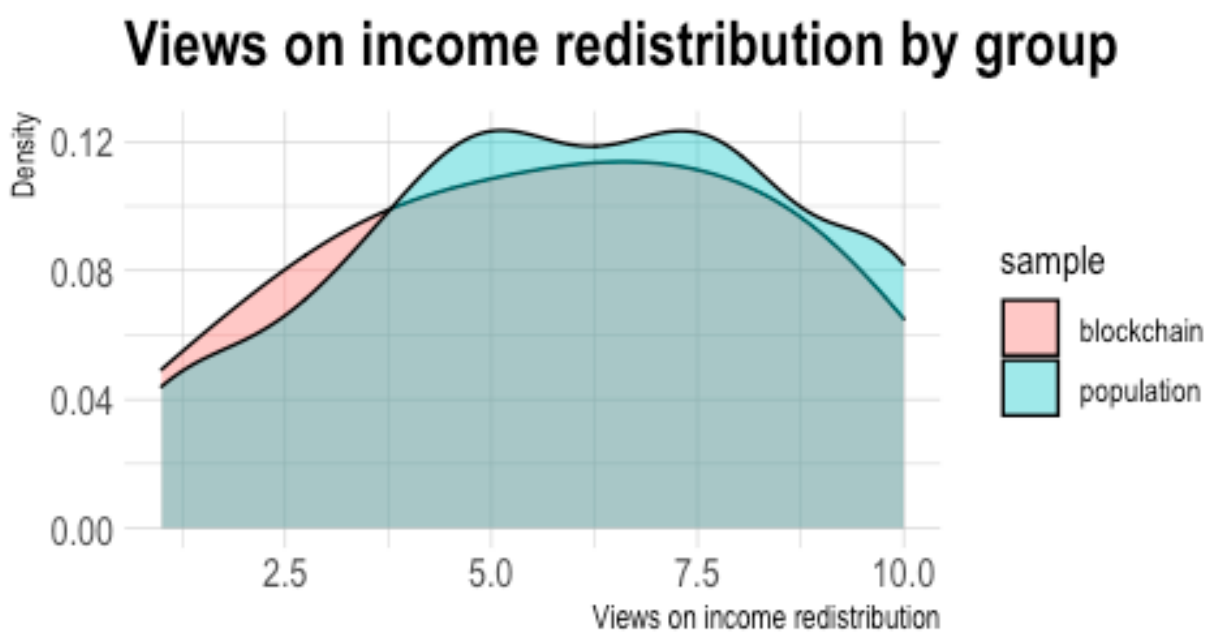

Figure A6.b: Views on income redistribution by group (WVS).

Views on income redistribution were calculated on scale from 1 (incomes should be made more equal) to 10 (there should be greater incentives for individual effort). Higher scores thus indicate less support for redistribution. The average view on income redistribution was 5.86 in the blockchain sample and 5.64 in the WVS sample $($ difference $=0.22, \mathrm{p}=0.399)$. 


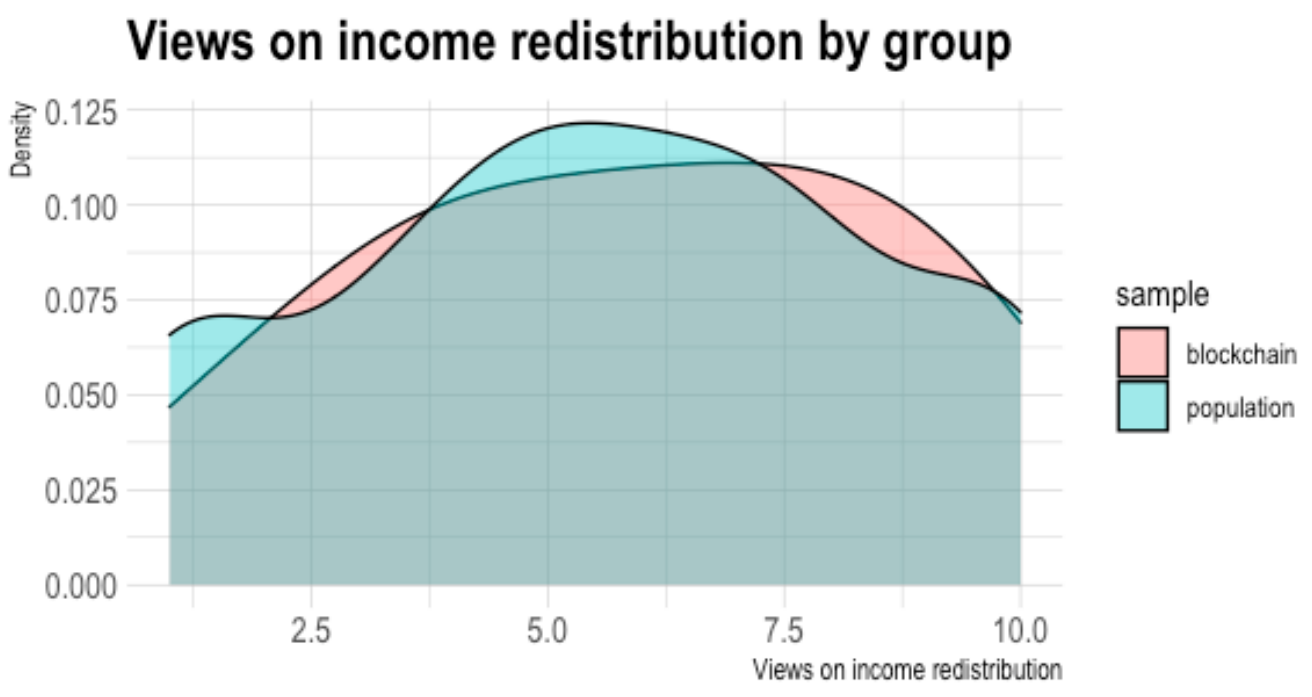

Figure A7: Views on science and technology making our lives healthier, easier, and more comfortable (WVS).

Views on science technology making our lives easier, healthier, and more comfortable were calculated on a scale from 1 (completely disagree) to 10 (completely agree). Higher scores thus indicate more favorable views on science and technology. The average view on science and technology was 8.17 in the blockchain sample and 7.57 in the WVS sample (difference $=0.50, \mathrm{p}=0.003$ ). 


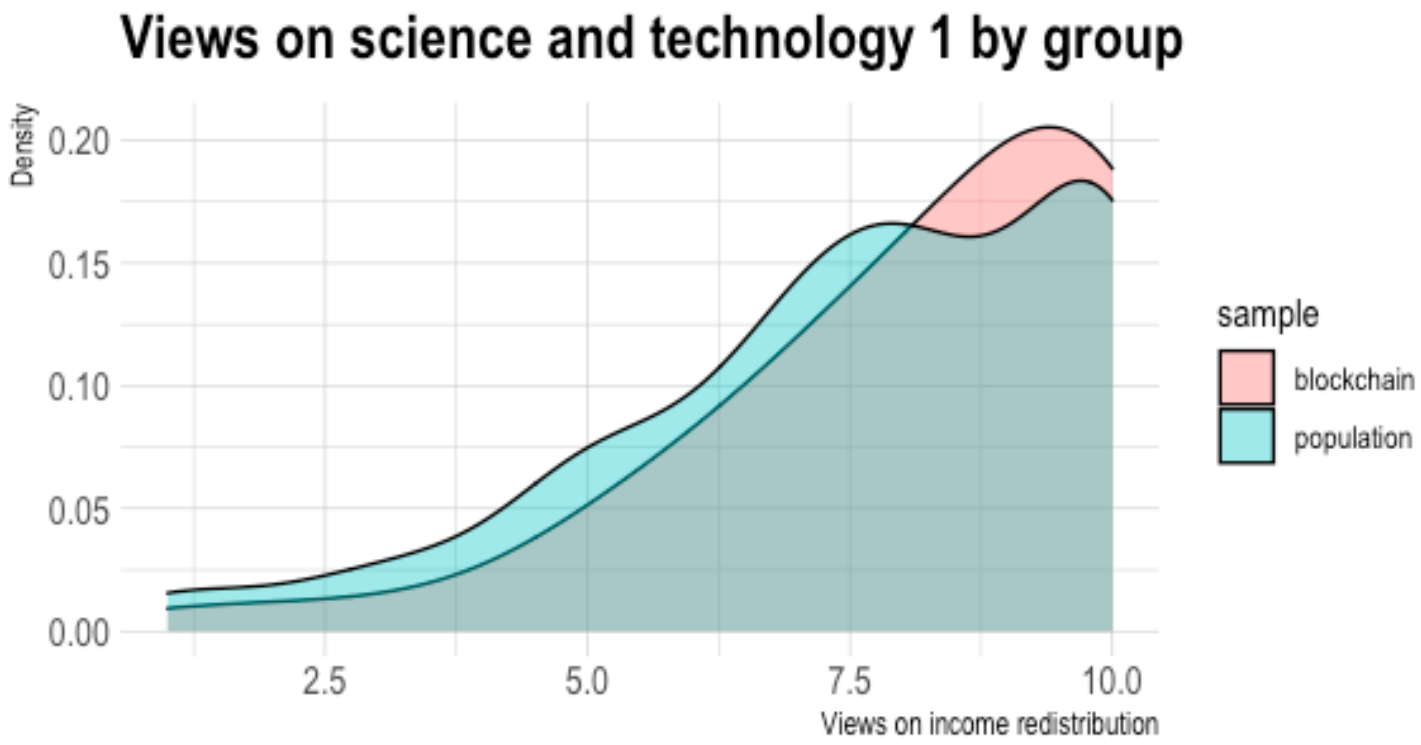

Figure A7: Views on because of science and technology there will be more opportunities for the next generation (WVS).

Views on because of science technology there will be more opportunities for the next generation were calculated on a scale from 1 (completely disagree) to 10 (completely agree). Higher scores thus indicate more favorable views on science and technology. The average view on science and technology was 7.93 in the blockchain sample and 7.58 in the WVS sample (difference $=0.35, \mathrm{p}=0.092$ ). 


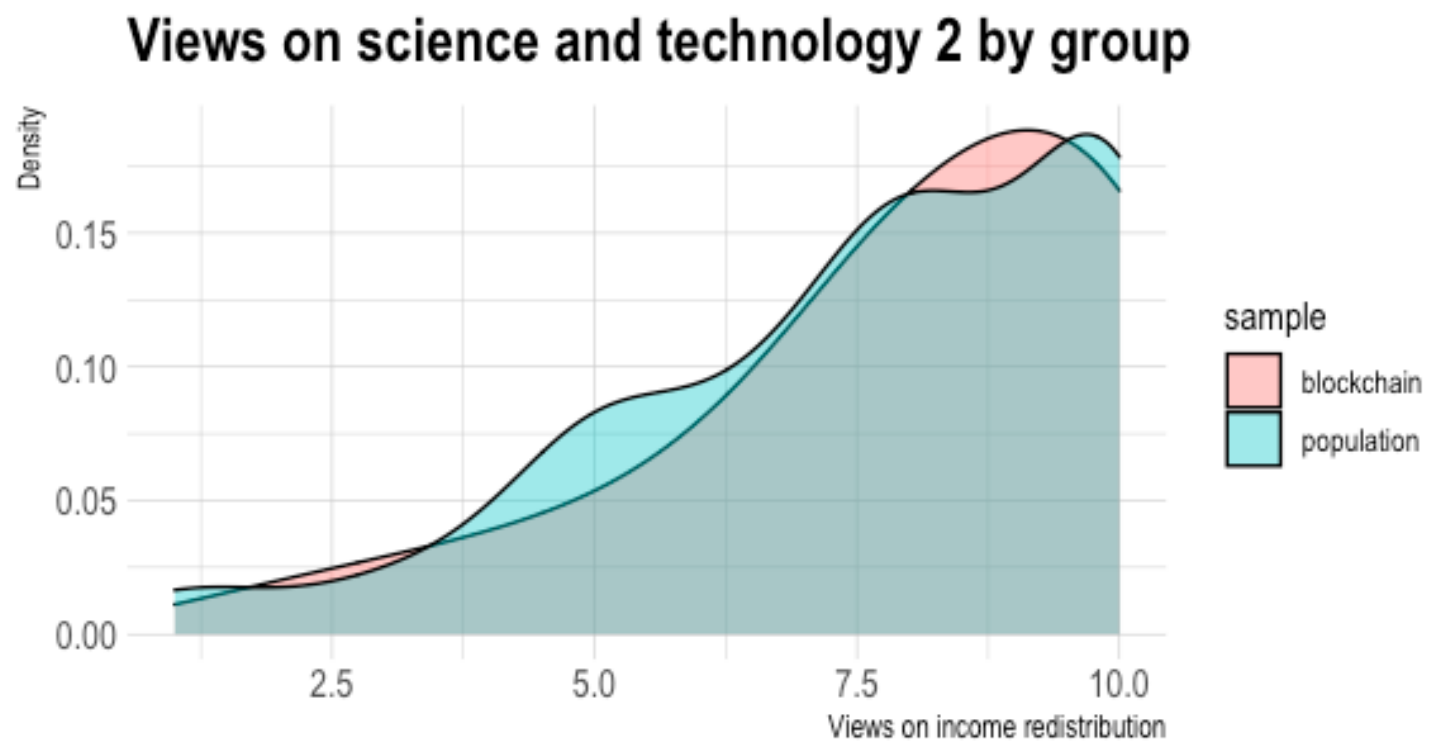

Figure A7: Views on all things considered the world is better off, or worse off, because of science and technology (WVS).

Views on all things considered the world is better off, or worse off, because of science and technology were calculated on a scale from 1 (a lot worse off) to 10 (a lot better off). Higher scores thus indicate more favorable views on science and technology. The average view on science and technology was 8.52 in the blockchain sample and 7.64 in the WVS sample (difference $=0.86, \mathrm{p}=0.000$ ). 


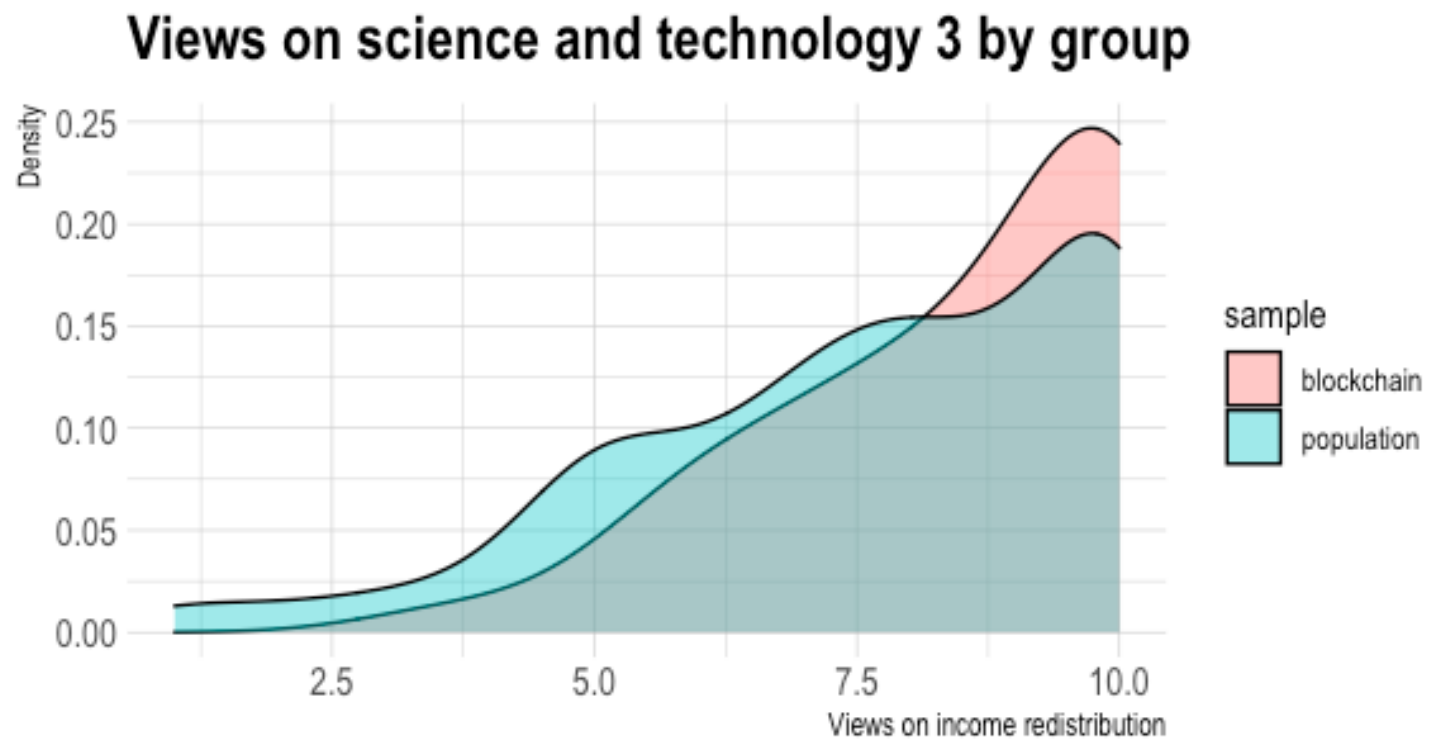

